\title{
How well do questionnaires on symptoms in neck-shoulder disorders capture the experiences of those who suffer from neck-shoulder disorders? A content analysis of questionnaires and interviews
}

\author{
Birgitta Wiitavaara*1,2, Martin Björklund ${ }^{3,4}$, Christine Brulin ${ }^{1}$ and \\ Mats Djupsjöbacka ${ }^{3}$
}

Address: ${ }^{1}$ Department of Nursing, Umeå University, S-901 87 Umeå, Sweden, ${ }^{2}$ Centre for Musculoskeletal Research, University of Gävle, S-801 76 Gävle, Sweden, ${ }^{3}$ Centre for Musculoskeletal Research, University of Gävle, Box 7629, S-907 12 Umeå, Sweden and ${ }^{4}$ Alfta Research Foundation, Box 94, S-822 22 Alfta, Sweden

Email: Birgitta Wiitavaara* - biawia@hig.se; Martin Björklund - martin.bjorklund@hig.se; Christine Brulin - christine.brulin@nurs.umu.se; Mats Djupsjöbacka - mats.djupsjobacka@hig.se

* Corresponding author

Published: 9 March 2009

BMC Musculoskeletal Disorders 2009, 10:30 doi:10.1186/147I-2474-10-30

This article is available from: http://www.biomedcentral.com/I47I-2474//0/30

(C) 2009 Wiitavaara et al; licensee BioMed Central Ltd.

This is an Open Access article distributed under the terms of the Creative Commons Attribution License (http://creativecommons.org/licenses/by/2.0), which permits unrestricted use, distribution, and reproduction in any medium, provided the original work is properly cited.
Received: 31 August 2008

Accepted: 9 March 2009

\begin{abstract}
Background: Previous research has indicated neck-shoulder disorders to have a fluctuating course incorporating a variety of symptoms. These findings awoke our interest to make a comparison between symptoms experienced by people affected with the disorder and the content of questionnaires that assess pain and other symptoms in neck-shoulder disorders. Thus the aims of this study were: -to explore the symptoms experienced by people with non-specific neck-shoulder problems, as well as experiences of nuances and temporal variations (fluctuations) of symptoms; -to investigate which sources were used in the development of ten questionnaires for assessing pain and other symptoms in the neck-shoulder; -to analyse the item content of the questionnaires; -to analyse the correspondence between the item content of the questionnaires and the symptoms described by the informants.
\end{abstract}

Methods: Content analysis of interviews with 40 people with non-specific neck-shoulder pain, and 10 questionnaires used to assess pain and other symptoms in neck-shoulder disorders.

Results: The interviews revealed a variety of symptoms indicating a bodily, mental/cognitive, and emotional engagement, and more general and severe symptoms than are usually considered in neck-shoulder questionnaires. Taking all questionnaires together many of the symptoms were considered, but most questionnaires only included a few of them. The informants were able to distinguish fluctuation of symptoms, and a variety of different qualities which were not usually considered in the questionnaires. Only two questionnaires had made use of the opinions of affected people in the development.

Conclusion: Few of the questionnaires had made use of the experiences of affected people in the development. The correspondence between the symptoms expressed by those affected and the content of the questionnaires was low. A variety of symptoms were expressed by the interviewees, and the participants were also able to distinguish nuances and fluctuations of symptoms. The present study points to the importance of other aspects than just pain and physical functioning as clinical trial outcome measures related to neck-shoulder disorders. To develop a condition-specific questionnaire, it is important to decide on the specific symptoms for the condition. Using the experiences of those affected, in combination with relevant research and professional knowledge, can enhance the validity of the questionnaires. 


\section{Background}

Musculoskeletal disorders are primarily a source of pain and human suffering, but they also have economic consequences, both for the individual and for society. Neck pain constitutes a large proportion of the musculoskeletal disorders. As much as $50 \%$ of the Swedish population is affected by neck pain at some point in life; this is comparable to international prevalence figures, which show a lifetime prevalence of $67-71 \%$ for neck pain [1]. The corresponding proportions for the point prevalence of neck pain varied between $12-22 \%$ [1]. Some recent studies also present similar results, showing a variation in the point prevalence between $21-43 \%$ for neck pain in Sweden and the Netherlands $[2,3]$ and $20 \%$ for neck-shoulder pain in Japan [4]. The proportion of individuals suffering from chronic neck pain (duration $>12$ weeks) has been estimated between $16-19 \%[2,5]$.

In general, the challenges related to musculoskeletal disorders are very complex since the knowledge on the pathophysiology is limited and a large number of potential risk factors have been identified [1]. In order to better understand and help people with neck pain, it is important to be able to measure this "pain and suffering" with valid questionnaires. One reasonable assumption for obtaining validity of questionnaires for any complex disorder or disease is that they are developed for the specific condition that they are intended to be used on. This, however, is not always the case, for example there are questionnaires for neck pain that are directly adapted from questionnaires for low back pain. Condition specific questionnaires would be valuable both in characterisation of the disorder and in evaluation of rehabilitative measures.

There are a number of ways to develop questionnaires for measuring pain and suffering. Generally, the questionnaires are based on theories or existing questionnaires, often from a professional perspective. It is important to take the experiences of those affected individual into consideration in the developmental process, which was also pointed out by several authors [6-9]. Consequently, an investigation of the experiences of sufferers could increase the face and content validity of the questionnaire via a higher relevance of the included items and adequacy of the questions for the intended use.

There is no consensus on how to investigate symptoms in neck-shoulder disorders neither in clinical practice nor in research. For instance, there is a wide variation in outcome measures in clinical trials for chronic pain, which makes comparison of treatment effects across studies difficult. The Initiative on Methods, Measurement, and Pain Assessment in Clinical Trials (IMMPACT) $[10,11]$ recommends the following core outcome domains to consider when designing clinical trials: pain, physical functioning, emotional functioning, global improvement, satisfaction with treatment, symptoms and adverse events. The authors associated with IMMPACT further point out the value of also taking different quality and temporal aspects into account in order to create a fuller description of a patient's pain experience than can be gained from considering intensity alone. This fuller description would then make it easier to identify treatments that are effective for certain aspects of pain, and also enable better evaluations.

In previous studies, we explored health experiences among people with musculoskeletal problems [12-14]. Our findings indicated that chronic neck-shoulder disorders can be experienced as a state of constant discomfort with intermittent periods of increasing illness and peaks of consuming intensity. We also found that a variety of different symptoms were related to the course of the disorder [14]. This varied cluster of symptoms awoke our interest to make a comparison to symptoms included in neck-shoulder questionnaires.

The aims of this study were:

- to explore the symptoms experienced by people with non-specific neck-shoulder problems, as well as experiences of nuances and temporal variations (fluctuations) of symptoms

- to investigate which sources were used in the development of ten questionnaires for assessing pain and other symptoms in the neck-shoulder

- to analyse the item content of the questionnaires

- to analyse the correspondence between the item content of the questionnaires and the symptoms described by the participants.

\section{Methods \\ Study design}

Content analysis was performed in three steps - analysis of the interviews, analysis of the questionnaires, and a comparison of the results. First, interviews were conducted with a number of people experiencing non-specific neck-shoulder disorders. The interviews were reviewed to find out which symptoms the participants felt were related to their musculoskeletal problems. Thereafter, a number of questionnaires on symptoms in neck-shoulder disorders were chosen on the basis of a review of the literature [15], an additional literature search and discussions in the research group. Questionnaires that only presented items concerning disability or dysfunction were excluded. The papers describing the questionnaires were reviewed according to which sources were used in the development 
of the questionnaires, and the questionnaires were analysed with regard to the items measuring pain and other symptoms. Finally, a comparison between the content of the questionnaires and the content of the interviews was performed.

\section{Interviews - data collection}

The informants constituted a convenience sample of 40 individuals, 25 women and 15 men (mean age 46.3 SD 7.8 ), with non-specific musculoskeletal problems in the neck-shoulder region. The participants were recruited via advertisements placed in a local paper in a medium-sized town in the middle of Sweden. Participants were primarily recruited to a larger project studying sensorimotor functions in chronic neck pain. The participants in that study were consecutively invited to participate in the present study until 40 participants were obtained. Everyone who was asked to participate in the interview study agreed to be interviewed, except one. The characteristics of the informants at the time of the interviews are presented in Table 1.

The interviews were semi-structured and made use of an interview guide, which had been developed on the basis of the results from two previous grounded theory studies

Table I: Characteristics of informants

\begin{tabular}{|c|c|c|}
\hline & $\mathrm{n}$ & $\%$ \\
\hline \multicolumn{3}{|l|}{ Sex } \\
\hline Women & 25 & 62.5 \\
\hline Men & 15 & 37.5 \\
\hline \multicolumn{3}{|l|}{ Last occupation } \\
\hline Blue collar & 21 & 52.5 \\
\hline White collar & 15 & 37.5 \\
\hline Self employed & 4 & 10 \\
\hline \multicolumn{3}{|l|}{ Occupational activity } \\
\hline $100 \%$ & 31 & 77.5 \\
\hline $75 \%$ & 2 & 5 \\
\hline $50 \%$ & 4 & 10 \\
\hline $25 \%$ & I & 2.5 \\
\hline $0 \%$ & 2 & 5 \\
\hline \multicolumn{3}{|c|}{ Previous periods of sick leave for MSD } \\
\hline Never & 18 & 45 \\
\hline Shorter periods & 12 & 30 \\
\hline$>3$ months & 10 & 25 \\
\hline \multicolumn{3}{|c|}{ Length of MSD problems } \\
\hline$<5$ years & 3 & 7.5 \\
\hline $5-9$ years & 4 & 10 \\
\hline $10-14$ years & 5 & 12.5 \\
\hline $15-19$ years & 5 & 12.5 \\
\hline$>20$ years & 14 & 35 \\
\hline Unable to specify & 9 & 22.5 \\
\hline
\end{tabular}

exploring the health experiences of people with musculoskeletal disorders $[12,13]$. The focus of the interviews was to explore the symptoms and their temporal variations that the participants related to their musculoskeletal problems. All interviews followed the same interview guide, and follow-up questions were used to elicit the participants' answers. The interview guide included the following questions:

- Where are your problems sited?

- Please describe what you experience.

- Do you experience your problems all the time, or is it off and on?

- Are your problems the same all the time or do they change/have they changed?

-What do you experience when your problems get worse?

- How do you feel when your problems are at their worst?

- How did your problems start?

- How did you first notice these problems?

\section{Interviews - analysis}

The interviews were analysed using content analysis [16] of the manifest content. First the interviews were read one by one, and all symptom descriptions that the participants related to their musculoskeletal problems were marked and a list of all symptoms was created. Then the interviews were re-read to check that nothing was missing in the symptom list. Next, the symptoms on the symptom list were collated into subcategories, which in turn were collated into categories and main categories. The categorisation was discussed within the research group as well as with two external specialists on musculoskeletal disorders. As a last step, the occurrence of each symptom in the sample was checked, and frequencies were calculated.

\section{Questionnaires - data collection}

Questionnaires that presented items concerning pain and other symptoms were included. The choice of questionnaires was firstly based on a systematic review of papers published between 1966 and 2000 that considered standard scales for measurement of functional outcome for cervical pain or dysfunction [15]. This review presented the following questionnaires as standard neck pain scales:

- The Neck Disability Index (NDI) [17]

- The Neck Pain and Disability Scale (NPDS) $[18,19]$ 
- The Patient-Specific Functional Scale Self-Reports with Neck Dysfunction (PSFS) [20]

- The Northwick Park Neck Pain Questionnaire (NPQ) [21].

The review of Pietrobon and colleagues [15] also included the Copenhagen Neck Functional Disability Scale [22], which was excluded from our study since it only concerned neck dysfunction.

Secondly, a complementary search for papers on questionnaires which were published between 2000 and March 2007 was performed on the PubMed database using the keywords: neck pain scale; neck pain and outcome measures; neck pain and questionnaire. The following scales were found and added to the analysis:

- The Bournemouth Questionnaire (BQ) [23]

- The Cervical Spine Outcome Questionnaire (CSOQ) [24]

- The Core Neck Pain Questionnaire (CNPQ) [25]

- The Extended Aberdeen Back Pain Scale (EABPS) (neck, shoulder, low back) [26].

Finally, two more questionnaires were added, as they were judged to be relevant:

- The Profile Fitness Mapping questionnaires (PFM) (Björklund, Hamberg, Heiden \& Barnekow-Bergkvist, In preparation)

- The Standardised Nordic Questionnaires (SNQ) [27].

The PFM questionnaire is region-specific and intended for assessment of symptoms and functional limitations in neck pain patients. The PFM was judged as relevant for this study, as the constructors of the scales made use of the experiences of people affected with chronic musculoskeletal problems in the development of the questionnaire. (Björklund et al. In preparation). Recently, a similar questionnaire intended for use among people with low back pain was tested for reliability and validity with good results [28]. The SNQ was added as it is often used in relation to musculoskeletal disorders. The SNQ consists of several different parts directed to different body regions. In the analysis in the present study the "Trouble with the locomotive organs" and "Questionnaire about neck and shoulder trouble" sections were chosen. In total, ten questionnaires were selected for analysis.

\section{Questionnaires - analysis}

As a first step, the papers presenting the different questionnaires were reviewed for data on sources used in the development of the questionnaires and the items included. Secondly, all items regarding pain and other symptoms included in the questionnaires were listed, and sorted into different categories according to content. Items concerning disability or dysfunction with no connection to musculoskeletal pain were excluded. Next, the different aspects of descriptions of pain and other symptoms in the items, along with the response scales, were analysed. Various aspects of fluctuations (such as different time perspectives) and nuances of symptoms were considered in this analysis. The different aspects of pain were then categorised as they were addressed by the different questionnaires. Next, all symptoms included in the questionnaires were categorised with respect to engagement. Finally, the results of the analyses of the interviews and the questionnaires were compared for correspondence.

\section{Ethical considerations}

The study was approved by the Regional Ethical Review Board in Uppsala (\# 2006-013), Sweden. The participants received information orally and via an introductory letter about the purpose and procedure of the study, about guaranteed confidentiality, and that both participation and the choice of which experiences to communicate were voluntary.

\section{Results \\ Interviews}

The content analysis of the symptoms expressed in the interviews resulted in three main categories, as the symptoms revealed an engagement that was of a bodily, mental/ cognitive and emotional nature. These main categories are presented in Table 2 along with their underlying categories, subcategories, and codes.

The bodily engagement consisted of the regions of the neck, the shoulder, the shoulder blades, the rest of the body and general engagement. The type of the symptoms of the neck, shoulder and shoulder-blade region were categorised as functional and as pain. In the neck, the functional symptoms were described, for example, as tenseness, stiffness, weakness, powerlessness, and lockings and/or wryneck. The experiences of pain were described in words as tenderness, gnawing, burning, stinging, cutting, throbbing, and pressure or pressuring ache. Unspecified ache/ pain was inherent in all the pain subcategories, as some participants had trouble describing their pain experiences. In the shoulder, the functional symptoms were perceived as, for example, tenseness, stiffness and tiredness. Among the experiences of pain were descriptions of tenderness, gnawing, burning and/or stinging, and pressure or pressuring ache. It is notable that the participants seemed to 
Table 2: Categorisation of all symptoms expressed in the interviews $(n=40)$

\begin{tabular}{|c|c|c|c|c|c|c|}
\hline Engagement & Body region & Type of symptom & Symptom & Correspondence* & $\mathrm{n}$ & $\%$ \\
\hline \multirow[t]{28}{*}{ Bodily } & Neck & Functional & Tenseness, stiffness & I & 34 & 85 \\
\hline & & & Creaking, cracking & 2 & 6 & 15 \\
\hline & & & Weakness, tiredness, powerlessness & $3-5$ & 11 & 28 \\
\hline & & & Locking, wryneck & 6 & 14 & 35 \\
\hline & & Pain & Tenderness & - & 4 & 10 \\
\hline & & & Gnawing, smarting & - & 16 & 40 \\
\hline & & & Burning, stinging & - & 10 & 25 \\
\hline & & & Cutting, pricking & - & 7 & 18 \\
\hline & & & Pulsating, pounding, throbbing & - & 4 & 10 \\
\hline & & & Pressure, pressuring ache & - & 8 & 20 \\
\hline & & & Unspecified ache/pain & $x$ & 8 & 20 \\
\hline & Shoulder & Functional & Tenseness, stiffness & 1 & 15 & 38 \\
\hline & & & Tiredness & 4 & 3 & 8 \\
\hline & & Pain & Tenderness & - & 7 & 18 \\
\hline & & & Gnawing, smarting & - & 11 & 28 \\
\hline & & & Burning, stinging & - & 6 & 15 \\
\hline & & & Pressure, pressuring ache & - & 4 & 10 \\
\hline & & & Unspecified ache/pain & $x$ & 9 & 23 \\
\hline & Shoulder blade & Functional & Tenseness, Stiffness & - & 10 & 25 \\
\hline & & Pain & Tenderness & - & 4 & 10 \\
\hline & & & Gnawing, smarting & - & 8 & 20 \\
\hline & & & Burning, stinging & - & 2 & 5 \\
\hline & & & Unspecified ache/pain & $x$ & 8 & 20 \\
\hline & Rest of the body & & Pain, numbness in arms & 7 & 18 & 45 \\
\hline & & & Headache & 8 & 22 & 55 \\
\hline & & & Ache, stiffness in jaw & 9 & 4 & 10 \\
\hline & & & Eyes; irritated, runny, tired, blurred vision & - & 3 & 8 \\
\hline & & & Throat; hoarseness, pain, cramps in larynx & 10 & 3 & 8 \\
\hline
\end{tabular}


Table 2: Categorisation of all symptoms expressed in the interviews $(n=40)$ (Continued)

\begin{tabular}{|c|c|c|c|c|}
\hline General & Dizziness & 12 & 3 & 8 \\
\hline & Nausea, Vomiting & 13 & 6 & 15 \\
\hline & $\begin{array}{l}\text { Cold symptoms, snottiness, feebleness, feeling out of } \\
\text { sorts }\end{array}$ & 13 & 1 & 3 \\
\hline \multirow[t]{4}{*}{ Mental/Cognitive } & Fatigue & 11 & 9 & 23 \\
\hline & Difficulty concentrating & 14 & 10 & 25 \\
\hline & Sensitivity to sound/light & 15 & 3 & 8 \\
\hline & (Burnout) & & 8 & 20 \\
\hline \multirow[t]{2}{*}{ Emotional } & Irritation, irritability & 17 & 18 & 45 \\
\hline & Sadness, depression & 16 & 6 & 15 \\
\hline
\end{tabular}

*See corresponding numbers in table 6 for comparison with symptoms included in the questionnaires. ( $x$ denotes unspecified symptoms, present in both table 2 and 6 , -denotes symptoms not included in any of questionnaires).

refer their symptoms to the muscular region between the neck and the shoulder, rather than to the area of the shoulder joint. In the shoulder blades, the functional symptoms were tenseness and stiffness, while the experiences of pain were, for example, tenderness and gnawing pain. In the rest of the body, the symptoms were pain and/ or numbness in the arms, headache, and ache and/or stiffness in the jaw. Symptoms from the eyes could be experienced as irritated, tired and/or runny eyes with blurry vision. Regarding the throat, there were symptoms such as hoarseness, pain, and cramp in the larynx. The participants also expressed a general engagement in the form of dizziness, nausea, and vomiting. In one case, even cold symptoms, such as being feeble, out of sorts, and snotty, were related to the coming and going of symptoms. Eight of the 40 participants also described symptoms of burnout, which may or may not have been related to their musculoskeletal

problems.

The mental/cognitive engagement that the participants related to their musculoskeletal problems was experienced as symptoms as fatigue; difficulties in concentrating; and sensitivity to sound and/or light. Finally, the emotional engagement manifested as symptom as irritation and/or irritability; and sadness and/or depression.

\section{Questionnaires}

Sources used in the development

A review of the papers that presented the different questionnaires showed that six questionnaires were modifications of low back scales (NDI, NPQ, NPDS, BQ, CNPQ, EABPS) $[17,18,21,23,26]$. Another, CSOQ, was developed based on literature on characteristics in neck disorders and treatment outcomes, and a consensus procedure involving health care professionals [24]. The SNQ was developed by a project group following the tradition of some earlier medical questionnaires [27]. Only EABPS and PFM had taken the experiences of those affected into consideration in the development process. The EABPS was refined by means of soliciting patients' views on the questionnaire [26]. The PFM was developed by deriving a symptom list using the experiences of 20 patients. This list was checked for "over-lapping" by a group of professionals, complemented after reviewing the literature, and then judged by the patients again (Björklund et al., In preparation). The PSFS was based on the concept of the patient generating a list of problems when answering the questionnaire [20]. A severe limitation in the PSFS' concept is that it only allows following up each individual and not comparisons between individuals.

\section{Overview of all symptoms included}

An initial basic content analysis was used to obtain an overview of all symptoms included in the questionnaires (Tables 3 and 4). The questionnaires differed in terms of which body regions were addressed, and the inclusion of other symptoms from the rest of the body; mental/cognitive engagement and emotional engagement also varied.

Pain (Tables 3 and 4) was considered as neck pain solely in BQ, NDI, NPDS, NPQ, and PFM, while pain from neckshoulder was considered in CNPQ, CSOQ, EABPS and SNQ. Other symptoms from neck-shoulder were included in a few of the questionnaires, for example, stiffness (NPDS, PFM), and tension, cracking, tiredness, weakness, and locking (PFM). Musculoskeletal symptoms and other 
Table 3: Overview all symptoms included in the questionnaires

\begin{tabular}{|c|c|c|c|c|c|c|c|}
\hline & \multicolumn{2}{|l|}{$\begin{array}{l}\text { Neck/shoulder } \\
\text { Symptoms }\end{array}$} & \multicolumn{2}{|c|}{$\begin{array}{l}\text { Symptoms from the } \\
\text { rest of the body }\end{array}$} & \multirow[t]{2}{*}{$\begin{array}{l}\text { Mental/Cogn. } \\
\text { Engagement }\end{array}$} & \multirow[t]{2}{*}{$\begin{array}{l}\text { Emotional } \\
\text { engagement }\end{array}$} \\
\hline Name & Focus & Pain & Other & $\begin{array}{l}\text { Musculo- } \\
\text { skeletal }\end{array}$ & Other & & \\
\hline $\begin{array}{l}\text { Bournemouth } \\
\text { Questionnaire } \\
\text { (BQ) }\end{array}$ & Neck & Neck pain & & & & $\begin{array}{l}\text { Difficulties } \\
\text { concentrating }\end{array}$ & $\begin{array}{l}\text { Anxiety (feeling } \\
\text { tense, uptight, } \\
\text { irritable, } \\
\text { difficulties } \\
\text { relaxing) } \\
\text { Depression } \\
\text { (feeling down- } \\
\text { in-the-dumps, } \\
\text { sad, in low } \\
\text { spirits, } \\
\text { pessimistic, } \\
\text { unhappy) }\end{array}$ \\
\hline $\begin{array}{l}\text { Cervical Spine } \\
\text { Outcome } \\
\text { Questionnaire } \\
\text { (CSOQ) }\end{array}$ & $\begin{array}{l}\text { Neck + } \\
\text { Shoulder arm }\end{array}$ & $\begin{array}{l}\text { Neck pain + } \\
\text { Shoulder-arm } \\
\text { pain }\end{array}$ & & $\begin{array}{l}\text { Pain shoulder- } \\
\text { arm and head } \\
\text { ache tingling in } \\
\text { arms or hands. } \\
\text { Numbness, } \\
\text { clumsiness or } \\
\text { weakness legs }\end{array}$ & $\begin{array}{l}\text { Difficulties } \\
\text { swallowing } \\
\text { Sleeping } \\
\text { difficulties } \\
\text { Felt sickly or } \\
\text { unwell } \\
\text { Felt low in } \\
\text { energy or } \\
\text { sluggish }\end{array}$ & & $\begin{array}{l}\text { Feeling jittery } \\
\text { or restless } \\
\text { Feeling anxious } \\
\text { or tense } \\
\text { Worry or } \\
\text { concern about } \\
\text { one's physical } \\
\text { health } \\
\text { Feeling sad, } \\
\text { discouraged or } \\
\text { hopeless }\end{array}$ \\
\hline $\begin{array}{l}\text { Core Neck Pain } \\
\text { Questionnaire } \\
\text { (CNPQ) }\end{array}$ & $\begin{array}{l}\text { Neck }+ \\
\text { Shoulder-arm }\end{array}$ & $\begin{array}{l}\text { Neck pain + } \\
\text { Shoulder-arm } \\
\text { pain }\end{array}$ & & & & & $\begin{array}{l}\text { Feelings about } \\
\text { spending the } \\
\text { rest of life with } \\
\text { these symptoms }\end{array}$ \\
\hline $\begin{array}{l}\text { Extended } \\
\text { Aberdeen Back } \\
\text { Pain Scale } \\
\text { (EABPS) }\end{array}$ & $\begin{array}{l}\text { Neck + } \\
\text { Shoulder-arm, } \\
\text { hand }\end{array}$ & $\begin{array}{l}\text { Pain neck, back } \\
\text { or limb } \\
\text { Pain arm, } \\
\text { shoulder }\end{array}$ & $\begin{array}{l}\text { Weak-ness or } \\
\text { loss of power: } \\
\text { shoulder }\end{array}$ & $\begin{array}{l}\text { Head ache } \\
\text { Pain arm; upper } \\
\text { arm, fore arm, } \\
\text { or wrist/hand } \\
\text { Weakness/loss } \\
\text { of power; upper } \\
\text { arm, fore arm, } \\
\text { or wrist/hand } \\
\text { Loss of feelings } \\
\text { in arms }\end{array}$ & $\begin{array}{l}\text { Sleeping } \\
\text { difficulties }\end{array}$ & & \\
\hline $\begin{array}{l}\text { Neck Disability } \\
\text { Index } \\
\text { (NDI) }\end{array}$ & Neck & Neck pain & & Head ache & $\begin{array}{l}\text { Sleeping } \\
\text { difficulties }\end{array}$ & $\begin{array}{l}\text { Affected ability } \\
\text { to concentrate }\end{array}$ & \\
\hline
\end{tabular}

symptoms from the rest of the body were included in some questionnaires. The SNQ asked for pain in all regions of the body except for the head. Musculoskeletal symptoms were considered as symptoms in the arm/hand (CNPQ, CSOQ, EABPS, NPQ, PFM), headache (CSOQ, EABPS, NDI), and jaw trouble (PFM). Other symptoms from the rest of the body considered in the questionnaires were sleeping difficulties (CSOQ, EABPS, NDI, NPDS, NPQ, PFM), feeling sickly/unwell/indisposed (CSOQ, PFM), feeling low in energy or sluggish (CSOQ), dizziness or balance disturbance (PFM), difficulty swallowing (CSOQ, PFM), and difficulty breathing (PFM). Mental/cognitive engagement was also considered in some questionnaires as an affected ability to concentrate/think clearly (BQ, NDI, NPDS, PFM), and sensitivity to sound and light (PFM). Emotional engagement was considered in some questionnaires and expressed in general as affected emotions (NPDS), mood disturbances (PFM), changed outlook on life (NPDS), and feelings about spending the rest of one's life with these symptoms (CNPQ); and in specifics as 
Table 4: Overview of all symptoms included in the questionnaires

\begin{tabular}{|c|c|c|c|c|c|c|c|}
\hline \multicolumn{2}{|c|}{ Instrument } & \multicolumn{2}{|c|}{ Neck/shoulder symptoms } & \multicolumn{2}{|c|}{$\begin{array}{l}\text { Symptoms from the } \\
\text { rest of the body }\end{array}$} & \multirow[t]{2}{*}{$\begin{array}{l}\text { Mental/Cogn. } \\
\text { Engagement }\end{array}$} & \multirow[t]{2}{*}{$\begin{array}{l}\text { Emotional } \\
\text { engagement }\end{array}$} \\
\hline Name & Focus & Pain & Other & $\begin{array}{l}\text { Musculo- } \\
\text { skeletal }\end{array}$ & Other & & \\
\hline $\begin{array}{l}\text { Neck Pain and } \\
\text { Disability Scale } \\
\text { (NPDS) }\end{array}$ & Neck & Neck pain & Neck stiffness & & $\begin{array}{l}\text { Sleeping } \\
\text { difficulties }\end{array}$ & $\begin{array}{l}\text { Affected ability } \\
\text { to think or } \\
\text { concentrate }\end{array}$ & $\begin{array}{l}\text { Changed } \\
\text { outlook on life } \\
\text { (depression, } \\
\text { hopelessness } \\
\text { etc.) Affected } \\
\text { emotions }\end{array}$ \\
\hline $\begin{array}{l}\text { Northwick Park } \\
\text { Neck Pain } \\
\text { Questionnaire } \\
\text { (NPQ) }\end{array}$ & Neck + arms & Neck pain & & $\begin{array}{l}\text { Arm pain. Pins } \\
\text { and needles in } \\
\text { arms. }\end{array}$ & $\begin{array}{l}\text { Sleeping } \\
\text { difficulties }\end{array}$ & & \\
\hline $\begin{array}{l}\text { Patient-Specific } \\
\text { Functional Scale } \\
\text { Self-Reports } \\
\text { with Neck- } \\
\text { Dysfunction } \\
\text { (PSFS) }\end{array}$ & $\begin{array}{l}\text { General, tested } \\
\text { pt with neck } \\
\text { dysfunction. }\end{array}$ & Neck pain & & & & & \\
\hline $\begin{array}{l}\text { Profile Fitness } \\
\text { Mapping } \\
\text { questionnaires } \\
\text { (PFM) }\end{array}$ & $\begin{array}{l}\text { Neck + arm- } \\
\text { hand }\end{array}$ & $\begin{array}{l}\text { Soreness Neck } \\
\text { pain }\end{array}$ & $\begin{array}{l}\text { Stiffness } \\
\text { Tension Cracks } \\
\text { Tiredness } \\
\text { Weakness } \\
\text { Lockings }\end{array}$ & $\begin{array}{l}\text { Fumblingness } \\
\text { hands } \\
\text { Numbness Jaw } \\
\text { trouble }\end{array}$ & $\begin{array}{l}\text { Disturbance of } \\
\text { balance } \\
\text { Dizziness } \\
\text { Indisposed } \\
\text { Disturbance of } \\
\text { swallowing } \\
\text { Disturbance of } \\
\text { breathing } \\
\text { Sleeping } \\
\text { difficulties }\end{array}$ & $\begin{array}{l}\text { Disturbance of } \\
\text { concentration } \\
\text { Sensitivity to } \\
\text { sound } \\
\text { Sensitivity to } \\
\text { light }\end{array}$ & $\begin{array}{l}\text { Irritability, short } \\
\text { tempered } \\
\text { Depressed } \\
\text { Stressed } \\
\text { Anxiety Mood } \\
\text { disturbances }\end{array}$ \\
\hline $\begin{array}{l}\text { Standardised } \\
\text { Nordic } \\
\text { Questionnaire } \\
\text { (SNQ) }\end{array}$ & $\begin{array}{l}\text { Neck }+ \\
\text { shoulder }+ \\
\text { whole loco- } \\
\text { motor system }\end{array}$ & Ache, pain & Discomfort & $\begin{array}{l}\text { Ache, pain \& } \\
\text { discomfort in: } \\
\text { elbow, hand/ } \\
\text { wrist, upper } \\
\text { back, low back, } \\
\text { hips, knees, } \\
\text { feet/ankles }\end{array}$ & & & \\
\hline
\end{tabular}

depression and hopelessness (BQ, CSOQ, NPDS, PFM), anxiety and tenseness (BQ, CSOQ, PFM), stress, irritability, and short temper (BQ, PFM), and worry about physical health (CSOQ).

\section{Different aspects of pain}

After the initial basic content analysis, a complementary analysis of the different aspects of pain and other symptoms in the questionnaires was performed. Any eventual consideration of aspects of fluctuations (using different time perspectives) and nuances of symptoms was also reviewed, and the different response scales used in the questionnaires were examined.

The results show that the only questionnaires that took any sort of quality of pain or other neck-shoulder symp- toms into consideration were the NPDS, which included neck stiffness, and PFM, which included soreness, stiffness, tension, cracking, tiredness, weakness, and locking. None of the reviewed questionnaires differentiated the sensory qualities of the neck pain, but some considered different qualities of shoulder and/or arm symptoms, such as pins and needles in the arms (NPQ), weakness or tingling in the arms or hands (CSOQ), loss of feeling, weakness, or loss of power in the arm or wrist/hand (EABP), and clumsy hands or numbness (PFM).

How the different aspects of pain were addressed

Pain intensity was the only aspect of pain (Table 5) that was measured by all questionnaires except for the SNQ. The SNQ instead measured prevalence of pain ever, last 12 months and seven days. Pain intensity was measured 
Table 5: How the different aspects of pain were addressed by the different questionnaires.

\begin{tabular}{|c|c|c|}
\hline Pain aspect & Addressed as & Questionnaire \\
\hline Prevalence & Ever, 12 months, 7 days & SNQ \\
\hline \multirow[t]{6}{*}{ Intensity } & & $\begin{array}{l}\text { All questionnaires } \\
\text { (SNQ if combined with VAS) }\end{array}$ \\
\hline & On an average (overall/over the past week/on a typical day) & BQ, CSOQ, NPDS \\
\hline & At its worst & CSOQ, NPDS \\
\hline & At its best & CSOQ \\
\hline & Related to different sorts of activity & BQ, CSOQ, EABPS, NDI, NPDS, PFM \\
\hline & Related to rest & CSOQ, PFM \\
\hline \multirow[t]{2}{*}{ Duration } & How many days in pain over the last 2 weeks? & EABPS \\
\hline & How many days in pain last 12 months? & SNQ \\
\hline Variation and duration & Continuous vs. intermittent symptoms, combined with duration & NPQ \\
\hline Frequency and intensity & How often? How much? & PFM \\
\hline \multirow[t]{6}{*}{ Temporal aspects of pain } & At the moment & CSOQ, NDI, NPDS, NPQ \\
\hline & Over the last 24 hours & NPQ, PSFS \\
\hline & Over the last I-2 weeks & BQ, CNPQ, EABPS, SNQ \\
\hline & Over the last 12 months & SNQ \\
\hline & Ever & SNQ \\
\hline & Compared to latest measurement & NPQ \\
\hline
\end{tabular}

as a rating of the average level (overall/over the past week/ on a typical day) (BQ, CSOQ NPDS,), at its worst (CSOQ, NPDS), and at its best (CSOQ). Pain intensity was also measured in relation to different types of activity (BQ, CSOQ, EABPS, NDI, NPDS, PFM) and rest (CSOQ, PFM). Duration was measured by EABPS (number of days in pain over the last two weeks), and SNQ (number of day in pain last 12 months), variation and duration by NPQ (continuous symptoms vs. on and off, combined with duration). Frequency and intensity were measured by PFM in combined scales ("How often?" and "How much?").

Different temporal aspects of pain were considered in some of the questionnaires. Pain was asked for: -at the moment (CSOQ, NDI, NPDS, NPQ), -last 24 hours (NPQ, PSFS), -last 1-2 weeks (BQ, CNPQ, EABPS, SNQ), -last 12 months (SNQ), -ever (SNQ), and -compared to last measurement (NPQ).

\section{Categorisation of all symptoms}

To facilitate the comparison between the different questionnaires and to the findings from the interviews, a categorisation of all symptoms included in the questionnaires was made with respect to engagement (Table 6) that was similar to the categorisation of the content of the interviews.

The symptoms considered by the constructors as important to include in the questionnaires were categorised as: bodily engagement with pain from the neck or neck-shoulder region, other neck symptoms, symptoms from the rest of the body; and general symptoms; also considered were mental/ cognitive and emotional engagement. None of the question- 
Table 6: Categorisation of all symptoms included in the questionnaires.

\begin{tabular}{|c|c|c|c|c|}
\hline Engagement & Body region & Symptom & Correspondence* & Questionnaire \\
\hline \multirow[t]{13}{*}{ Bodily } & Neck only & Pain & $x$ & BQ, NDI, NPDS, NPQ, PFM, PSFS \\
\hline & Neck-shoulder & Pain & $x$ & CNPQ, CSOQ, EABPS, SNQ \\
\hline & Other neck symptoms & Stiffness & 1 & NPDS, PFM \\
\hline & & $\begin{array}{l}\text { Tension, cracking, tiredness, weakness, } \\
\text { locking }\end{array}$ & $2-6$ & PFM \\
\hline & Rest of the body & Symptoms in arm/hand & 7 & $\begin{array}{l}\text { CNPQ, CSOQ, EABPS, NPQ, PFM, } \\
\text { SNQ }\end{array}$ \\
\hline & & Headache & 8 & CSOQ, EABPS, NDI \\
\hline & & Jaw trouble & 9 & PFM \\
\hline & & Difficulty swallowing & 10 & CSOQ, PFM \\
\hline & & Difficulty breathing & - & PFM \\
\hline & General & Sleeping difficulties & - & $\begin{array}{l}\text { CSOQ, EABPS, NDI, NPDS, NPQ, } \\
\text { PFM }\end{array}$ \\
\hline & & Feeling low in energy/sluggish & 11 & CSOQ \\
\hline & & Dizziness or balance disturbance & 12 & PFM \\
\hline & & Feeling sickly/unwell/indisposed & 13 & CSOQ, PFM \\
\hline \multirow[t]{2}{*}{ Mental/Cognitive } & & Difficulty concentrating/thinking clearly & 14 & BQ, NDI, NPDS, PFM \\
\hline & & Sensitivity to light/sound & 15 & PFM \\
\hline \multirow[t]{5}{*}{ Emotional } & & Affected emotions & $x$ & NPDS \\
\hline & & Depression, hopelessness & 16 & BQ, CSOQ, NPDS, PFM \\
\hline & & Anxiety, tenseness & - & BQ, CSOQ, PFM \\
\hline & & Irritability, short temper & 17 & BQ, PFM \\
\hline & & Worry about physical health & - & CNPQ, CSOQ \\
\hline
\end{tabular}

\footnotetext{
* See corresponding numbers in table 2 to compare with symptoms expressed by the interviewees. ( $x$ denotes unspecified symptoms which are
} present in both table 2 and 6, -denotes symptoms not expressed by the interviewees).

naires covered all the symptoms included in this categorisation. PFM included 15 different symptoms, CSOQ ten, NPDS six, BQ five, EABPS and NDI four, CNPQ and NPQ three, SNQ two, and PSFS one. The distribution of symptom regions (other than neck or neck-shoulder pain) included in the different questionnaires was as follows: other neck symptoms in two questionnaires (NPDS, PFM), symptoms from the rest of the body were included in seven (CNPQ, CSOQ, EABPS, NDI, NPQ, PFM, SNQ), general symptoms in six (CSOQ, EABPS, NDI, NPDS, NPQ, PFM), mental/cognitive symptoms in four (BQ, NDI, NPDS, PFM), and emotional symptoms in five (BQ, CNPQ, CSOQ, NPDS PFM). PFM had the best coverage, with five aspects of symptoms included (beside the neck or neck-shoulder pain). NPDS included four aspects, NDI and CSOQ three, BQ, CNPQ, EABPS, NPQ and SNQ included one aspect, while PSFS included only pain from the neck region. 


\section{Correspondence between questionnaires and interviews}

We found both similarities and differences between the specific symptoms described in the interviews and the symptoms included in the questionnaires. It is important to note that the following comparisons were made to the questionnaires taken all together, as a whole; when comparing to each of the questionnaires separately, the correspondence in most cases was low. The following comparisons are summarised under correspondence in Tables 2 and 6, in which the numbers after each symptom correspond to the occurrence of that symptom in the other table, and a dash (-) indicates that the symptom was not found in the data presented in the other table.

All functional symptoms from the neck derived from the interviews were found in the questionnaires as tenseness, stiffness, weakness, tiredness, powerlessness, cracking, and locking. According to the pain experiences the interviews revealed a qualitative differentiation which was not considered in the questionnaires. The functional symptoms from the shoulder described in the interviews might have been considered in the questionnaires as tenseness, stiffness, and tiredness in neck-shoulder. The differentiated pain symptoms from the shoulder described in the interviews were not considered in the questionnaires. In the interviews, some functional symptoms and pain symptoms from the shoulder blade region were described, while no such symptoms were included in the questionnaires. For the rest of the body, symptoms as pain and/or numbness in arms, headache, ache and/or stiffness in the jaw and throat symptoms were present in both interviews and questionnaires. Eye symptoms, which were not considered in the questionnaires, were mentioned by a few of the participants. General engagement was present in the interviews as dizziness, nausea, vomiting, cold symptoms, feebleness, and feeling out of sorts. This was interpreted as corresponding to feeling sickly/unwell/indisposed. Mental/cognitive engagement, expressed as fatigue, difficulty concentrating, and sensitivity to sound and light, was present in both interviews and questionnaires. In the interviews, eight people described symptoms of burnout, which might be a side finding as the participants did not relate those symptoms directly to their neck-shoulder disorder but may be worth further investigation. In terms of emotional engagement, irritation and irritability, and sadness and depression, were considered in both interviews and questionnaires.

Once again, it should be noted that these comparisons include the questionnaires as a group, and not separately. No single questionnaire covered all symptoms from the interviews. The PFM was the most comprehensive of the questionnaires (Table 6).
Conversely, the questionnaires did cover a couple of aspects that are not presented in the categorisation of the interviews. Firstly, sleeping difficulties, which were not interpreted as a symptom, per se, as the participants attributed their sleeping difficulties to their pain and other symptoms. Therefore it is not included in the categorisation presented in Table 2, even though it was present in the interviews. Nevertheless, as we know that sleeping problems have an adverse effect on health, it seems sound to also include in questionnaires. Secondly, breathing difficulties, which were not mentioned at all in the interviews.

\section{Summary of results}

- The narratives of men and women with neck-shoulder disorders revealed a variety of symptoms related to such disorders.

- These symptoms showed a bodily, mental/cognitive, and emotional engagement, and included more general and more severe symptoms than are usually found in neck-shoulder questionnaires.

- Few neck-shoulder questionnaires were developed using the experiences of those affected.

- Most neck-shoulder questionnaires covered only a minority of the symptoms presented by people with neckshoulder disorders.

- Mental/cognitive and emotional engagement, presented as significant symptoms by the participants, was often overlooked in the questionnaires.

- The fluctuations of symptoms were usually not taken into consideration.

- The nuances of symptoms were rarely considered.

\section{Discussion}

There is increasing agreement regarding the value of taking the experiences of those affected into consideration in the development of health status measurements [6-9], but this is still a rare practice in the area of musculoskeletal disorders. The usual sources of items in questionnaires are published literature, health professionals, and existing questionnaires [6]; this was also the case with the ten questionnaires reviewed in the present study. Six out of ten of the reviewed questionnaires were modified low back questionnaires. Only two questionnaires (EABPS, PFM) had used the opinions of those affected in the development process. The development process of EABPS used opinions on whether the questions were unclear, badly phrased, annoying, or unnecessary, or if any issue was omitted; this is a procedure which mostly relates to the 
face validity of the questionnaire. On the other hand, the PFM used symptom experiences to decide which items to include, a method which seems more likely to enhance the content validity. The PFM, which used the symptom experiences of 20 people with neck-shoulder problem in its development, seems to better reflect the significant aspects, as it had the greatest correspondence to the content of the interviews performed in our study. A number of researchers have emphasised the need to develop and choose instruments that fit the target group and the purpose of the evaluations $[8,15]$. Many neck-shoulder questionnaires are modifications of low back scales. A better approach might be to consider the content and items of several existing neck-shoulder questionnaires and the experiences of people with the disorder in order to increase the possibility of reflecting significant aspects of the disorder and thereby improve the content validity of the questionnaire.

Most of the analysed neck-shoulder questionnaires covered only a minority of the symptoms presented by people with neck-shoulder problems. The Initiative on Method, Measurement, and Pain Assessment in Clinical Trials (IMMPACT) have recommended some core outcome domains to consider when designing clinical pain trials, i.e. pain, physical functioning, emotional functioning, global improvement, satisfaction with treatment, symptoms and adverse events $[10,11]$. In terms of pain and functional symptoms, we noted that none of the reviewed questionnaires included symptoms from the shoulder blade region, a region mentioned by $25 \%$ of the participants. Emotional functioning is also often overlooked. The questionnaires that considered several aspects of emotional engagement were BQ, CSOQ, and PFM; the others either asked diffusely or not at all. The IMMPACT group has presented the result of a survey among people with pain, regarding their view of important outcome domains for chronic pain clinical trials [29]. The aspects that were judged to be the most important, in addition to pain reduction, were enjoyment of life, emotional wellbeing, fatigue, weakness and sleep-related problems. These findings are in line with the results of the present study and point at the importance of other aspects than just pain and physical functioning as outcome measures. Mental/cognitive engagement is not one of the suggested outcome domains of Dworkin and collegaues [10,11]. However, it was clearly present as difficulty concentrating/ thinking in four of the analysed questionnaires (BQ, NDI, NPDS, PFM), and as sensitivity to sound and light in one (PFM). The mental/cognitive engagement mentioned in the interviews included difficulty concentrating and sensitivity to sound/light, but also fatigue, which was experienced by about one-fourth of the participants. To increase the content validity of a neck-specific questionnaire, these aspects should also be included.
The fluctuation of symptoms is usually not taken into consideration in questionnaires, and similarly the nuances of symptoms are not considered. These aspects seem to be of great importance in relation to musculoskeletal disorders, as a great variability of the course of the disorder including a variety of symptoms is inherent in such conditions [30-33]. An exploratory study of the experience of bodily illness among people with chronic neckshoulder problems [14] describe a course of the disorder which is characterised by uncontrollable fluctuations. On a daily basis, most of the participants experienced constant discomfort; on top of this they reported intermittent fluctuations in symptom intensity and periods of peak intensity. By taking different quality and temporal aspects into consideration, as recommended by Dworkin and colleagues [10], it is possible to better capture the patient's symptom experience and thereby increase the possibility of identifying treatments effective for certain aspects of symptoms, and also enable better evaluations.

Another of the six domains to consider in clinical pain trials comprises adverse events [10]. In the above mentioned interview study regarding the disease course of chronic neck-shoulder problems [14], moments of consuming intensity were described, an aspect which might be included in this domain. Some of the participants in the previous study and in the present study described symptoms of a general bodily engagement with different symptoms during intense periods. This engagement included symptoms from eyes and throat, dizziness, vomiting, feebleness, and feeling out of sorts. This intensity aspect of the variable symptoms is often not taken into consideration, and could be an area worth studying further.

The participants were able to distinguish a variety of different qualities or nuances of symptoms related to the different regions. Different approaches to facilitate the description and measurement of pain have been considered in general pain questionnaires, such as the McGill Pain Questionnaire (MPQ) [34,35]. Melzack [34,35] identified a variety of pain descriptors which he categorised into four major groups; sensory, affective, evaluative, and miscellaneous. Different temporal aspects were also considered, such as whether the pain was experienced as rhythmic, periodic, intermittent, continuous, steady, or constant. Taking such an approach to musculoskeletal disorders could increase the possibility of capturing the fluctuations of symptoms, thus potentially increasing both the criterion-related validity (the ability to predict some criterion variable, such as the course of the underlying disease) and the responsiveness (the ability to detect small but important clinical changes) [15].

To develop a condition-specific questionnaire it is important to decide on the specific symptoms for the condition. 
A good way to do this is by using the symptom experiences of those affected, combined with relevant research and professional knowledge. The use of a combination of insider/outsider perspectives and qualitative/quantitative methods is needed if we are to successfully develop a questionnaire that captures the spectrum of symptoms experienced by individuals suffering from neck-shoulder pain in order to alleviate the suffering of those affected.

\section{Conclusion}

Even though musculoskeletal epidemiology over the last decades has recognized the multidimensionality of the disorders, there still remain some issues related to neckshoulder disorders (as well as to musculoskeletal disorders in general). One is that pain and disability often are the only aspects that are considered as relevant measures. Another is the use of a variety of combinations of different questionnaires measuring different aspects, and/or a selection of questions from these questionnaires. This, combined with different definitions of the disorders and included body regions, makes it difficult or impossible to accurately depict the problem, evaluate results and to make comparisons between studies. As it is reasonable to suppose that there are considerable differences in the multidimensionality between different musculoskeletal disorders, focus on measurement of neck-shoulder pain is needed.

Although there is increasing agreement regarding the value of taking the experiences of those affected into consideration in the development of health status measurements, this is still a rare practice in the area of neckshoulder pain. The present study shows that few of the analysed questionnaires used were developed using the experiences of people affected with the disorders. Instead, many of the questionnaires were modifications of low back scales. A better approach might be to consider the content and items of several existing neck-shoulder questionnaires and the experiences of people with the disorder in order to increase the possibility of reflecting significant aspects of the disorder and thereby improve the content validity of the questionnaire.

A variety of symptoms were expressed by the interviewees. The symptom experiences revealed a bodily, mental/cognitive, and emotional engagement, and included more severe symptoms than are usually related to neck-shoulder disorders. The participants were also able to distinguish a variety of different qualities or nuances of symptoms related to the different regions, as well as fluctuations of symptoms.

The correspondence between the separate questionnaires and the experiences of those affected was low; most of the analysed neck-shoulder questionnaires covered only a minority of the symptoms presented by people with neckshoulder problems. Mental and emotional engagement was often overlooked in the questionnaires, and fluctuations and nuances of symptoms were rarely considered. These aspects seem to be of great importance in relation to musculoskeletal disorders, as a great variability of the course of the disorder including a variety of symptoms is inherent in such conditions.

The present study points at the importance of other aspects than just pain and physical functioning as clinical trial outcome measures related to neck-shoulder disorders. By also taking different quality and temporal aspects into consideration, it is possible to better capture the patient's symptom experience and thereby increase the possibility of identifying treatments effective for certain aspects of symptoms, and also enable better evaluations.

\section{Competing interests}

The authors declare that they have no competing interests.

\section{Authors' contributions}

$\mathrm{BW}, \mathrm{CB}$ and MD participated in the design of the study. BW performed the data collection. BW and $\mathrm{CB}$ were responsible for the analysis of data. All authors (BW, $\mathrm{MB}$, $\mathrm{CB}$ and $\mathrm{MD}$ ) participated in the drafting of the manuscript, and the revision of the draft. All authors (BW, MB, $\mathrm{CB}$ and $\mathrm{MD}$ ) read and approved the final manuscript.

\section{References}

I. SBU: Back and neck pain. A systematic Review. The Swedish council on technology assessment in health care 2000 [http:// www.sbu.supload/Publikationer/Content0///ontiryggen 2000/ innehryggen full.html].

2. Guez M, Hildingsson C, Nilsson M, Toolanen G: The prevalence of neck pain - A population-based study from northern Sweden. Acta Orthopaedica Scandinavica 2002, 73(4):455-459.

3. Picavet HSJ, Schouten J: Musculoskeletal pain in the Netherlands: prevalences, consequences and risk groups, the DMC3-study. Pain 2003, I 02(I-2): 167-178.

4. Suka M, Yoshida K: Musculoskeletal pain in Japan: prevalence and interference with daily activities. Modern Rheumatology 2005, I 5(I):4I-47.

5. Wijnhoven HAH, de Vet HCW, Picavet HSJ: Prevalence of musculoskeletal disorders is systematically higher in women than in men. Clinical Journal of Pain 2006, 22(8):71 7-724.

6. Bombardier C, Tugwell P: Methodological considerations in functional assessment. Journal of Rheumatology 1987, I 4:6-10.

7. Guyatt GH, Feeny DH, Patrick DL: Measuring health-related quality-of-life. Annals of Internal Medicine 1993, I I 8(8):622-629.

8. Hoving JL, O'Leary EF, Niere KR, Green S, Buchbinder R: Validity of the neck disability index, Northwick Park neck pain questionnaire, and problem elicitation technique for measuring disability associated with whiplash-associated disorders. Pain 2003, I 02(3):273-28I.

9. Streiner DL, Norman GR: Health measurement scales: a practical guide to their development and use. 2nd edition. New York: Oxford University Press; 1995.

10. Dworkin RH, Turk DC, Farrar JT, Haythornthwaite JA, Jensen MP, Katz NP, Kerns RD, Stucki G, Allen RR, Bellamy N, et al.: Core outcome measures for chronic pain clinical trials: IMMPACT recommendations. Pain 2005, II3(I-2):9-19.

II. Dworkin RH, Turk DC, Wyrwich KW, Beaton D, Cleeland CS, Farrar JT, Haythornthwaite JA, Jensen MP, Kerns RD, Ader DN, et al.: Interpreting the clinical importance of treatment outcomes in 
chronic pain clinical trials: IMMPACT recommendations. Journal of Pain 2008, 9(2): 105-121.

12. Wiitavaara B, Lundman B, Barnekow-Bergkvist M, Brulin C: Striking a balance - health experiences of male ambulance personnel with musculoskeletal symptoms: A grounded theory. International Journal of Nursing Studies 2007, 44(5):770-779.

13. Wiitavaara B, Barnekow-Bergkvist M, Brulin C: Striving for balance: A grounded theory study of health experiences of nurses with musculoskeletal problems. International Journal of Nursing Studies 2007, 44(8): I379-1390.

14. Wiitavaara B, Brulin C, Barnekow-Bergkvist M: When the body makes itself heard - The experience of bodily illness among people with neck-shoulder problems. Advances in physiotherapy 2008, I0(2):85-94.

15. Pietrobon B, Coeytaux RB, Carey TS, Richardson WJ, DeVellis RF: Standard scales for measurement of functional outcome for cervical pain or dysfunction - A systematic review. Spine 2002, 27(5):5I5-522.

16. Graneheim $\mathrm{UH}$, Lundman B: Qualitative content analysis in nursing research: concepts, procedures and measures to achieve trustworthiness. Nurse Education Today 2003, 24:105-112

17. Vernon H, Mior S: The Neck Disability Index - A study of reliability and validity. Journal of Manipulative and Physiological Therapeutics 1991, 14(7):409-415.

18. Wheeler AH, Goolkasian P, Baird AC, Darden BV: Development of the neck pain and disability scale - Item analysis, face, and criterion-related validity. Spine 1999, 24(13): 1290-1294.

19. Goolkasian P, Wheeler AH, Gretz SS: The Neck Pain and Disability Scale: Test-retest reliability and construct validity. Clinical Journal of Pain 2002, I8(4):245-250.

20. Westaway MD, Stratford PW, Binkley JM: The patient-specific functional scale: Validation of its use in persons with neck dysfunction. Journal of Orthopaedic \& Sports Physical Therapy 1998 , 27(5):33।-338.

21. Leak AM, Cooper J, Dyer S, Williams KA, Turnerstokes L, Frank AO: The Northwick-Park-Neck-Pain-Questionnaire, devised to measure neck pain and disability. British Journal of Rheumatology 1994, 33(5):469-474.

22. Jordan A, Manniche C, Mosdal C, Hindsberger C: The Copenhagen neck functional disability scale: $A$ study of reliability and validity. Journal of Manipulative and Physiological Therapeutics 1998 $2 I(8): 520-527$.

23. Bolton JE, Humphreys BK: The Bournemouth Questionnaire: A short-form comprehensive outcome measure. II. Psychometric properties in neck pain patients. Journal of Manipulative and Physiological Therapeutics 2002, 25(3): | $4|-| 48$.

24. BenDebba M, Heller J, Ducker TB, Eisinger JM: Cervical spine outcomes questionnaire - Its development and psychometric properties. Spine 2002, 27(19):2||6-2|23.

25. White $P$, Lewith G, Prescott $P$ : The core outcomes for neck pain: Validation of a new outcome measure. Spine 2004, 29(17): 1923-1930.

26. Williams NH, Wilkinson C, Russell IT: Extending the Aberdeen Back Pain Scale to include the whole spine: a set of outcome measures for the neck, upper and lower back. Pain 200I, 94(3):26I-274.

27. Kuorinka I, Jonsson B, Kilbom A, Vinterberg $H$, Bieringsorensen $F$, Andersson G, Jorgensen K: Standardised Nordic Questionnaires for the analysis of musculoskeletal symptoms. Applied Ergonomics 1987, I 8(3):233-237.

28. Bjorklund M, Hamberg J, Heiden M, Barnekow-Bergkvist M: The assessment of symptoms and functional limitations in low back pain patients: validity and reliability of a new questionnaire. European Spine Journal 2007, I6(I I): I799-18II.

29. Turk DC, Dworkin RH, Revicki D, Harding G, Burke LB, Cella D, Cleeland CS, Cowan P, Farrar JT, Hertz S, et al.: Identifying important outcome domains for chronic pain clinical trials: An IMMPACT survey of people with pain. Pain 2008, I 37(2):276-85. Epub 2007 Oct I5

30. Von Korff M: Studying the natural history of back pain. Spine 1994, I 5( I 9 ( I 8 SuppI)):204IS-2046S.

31. Von Korff MSK: The course of back pain in primary care. Spine 1996, I 5(24(21)):2833-2837. discussion 2838-2839

32. Aublet-Cuvelier A, Aptel M, Weber H: The dynamic course of musculoskeletal disorders in an assembly line factory. Inter- national Archives of Occupational and Environmental Health 2006, 79(7):578-584.

33. Bot SD, Waal JM van der, Terwee CB, Windt DA van der, Schellevis FG, Bouter LM, Dekker J: Incidence and prevalence of complaints of the neck and upper extremity in general practice. Annals of the Rheumatic Diseases 2005, 64(I): I I8-123.

34. Melzack R: The McGill pain questionnaire: major properties and scoring methods. Pain 1975, I:277-299.

35. Melzack R: The McGill pain questionnaire - From description to measurement. Anesthesiology 2005, 103(1):199-202.

\section{Pre-publication history}

The pre-publication history for this paper can be accessed here:

http://www.biomedcentral.com/1471-2474/10/30/pre pub
Publish with Biomed Central and every scientist can read your work free of charge

"BioMed Central will be the most significant development for disseminating the results of biomedical research in our lifetime. "

Sir Paul Nurse, Cancer Research UK

Your research papers will be:

- available free of charge to the entire biomedical community

- peer reviewed and published immediately upon acceptance

- cited in PubMed and archived on PubMed Central

- yours - you keep the copyright 